\title{
DE „CONTROLLER” IN DE NEDERLANDSE VAKLITERATUUR MET ENKELE AANTEKENINGEN OVER ZIJN FUNCTIE EN PLAATS
}

\author{
door H. C. Treffers
}

Gevolg gevende aan de door Prof. Dr. H. J. van der Schroeff met zoveel enthousiasme gedane oproep (o.m. M.A.B. mei/juni 1953 en mei 1954) om de functie en de plaats van de controller nader in studie te nemen en deze te bezien vanuit de in ons land geldende verhoudingen, komt het mij nuttig voor allereerst aandacht te schenken aan de stand van het vraagstuk in de Nederlandse vakliteratuur. Niet alleen acht ik de kans aanwezig, dat hierdoor de in discussies met vakgenoten onmiskenbaar blijkende verwarring, althans voor een deel, wordt weggenomen, tevens vind ik daarin een zekere rechtvaardiging tegenover de eigen vakliteratuur, met alle erkenning overigens van het nut van kernachtige slogans, waaraan de in de jongste tijd veelvuldig geciteerde Amerikaanse publicaties zo rijk zijn.

Voor de beoordeling van de stand van het vraagstuk in de Nederlandse vakliteratuur is het nuttig in herinnering te roepen, dat Van der Schroeff de inhoud van de functie van de controller aanduidt met het vermelden van de volgende, zeer in het kort weergegeven, vier hoofdtaken.

1. Preparation

2. Operation

3. Interpretation

4. Recommendation and presentation

Het spreekt vanzelf, dat bij het vervullen van deze hoofdtaken de controller beschikt over een eigen apparaat, een staf van medewerkers en assistenten dus.

Volgens Van der Schroeff zijn het vooral de taken sub 3 en 4 , die in Amerika ,zó op de voorgrond staan, dat zij een nieuwe inhoud aan de functie geven". Vooral in deze beide taken strekken zich, aldus Van der Schroeff, de contacten met anderen in het bedrijf veel verder uit dan bij ons gebruikelijk is. In hoeverre deze constatering voor ons land in overeenstemming is met de feitelijke verhoudingen in de bedrijven, is uiteraard moeilijk vast te stellen. Vermoedelijk zullen zich daarbij allerlei schakeringen voordoen, waarbij echter wel kan worden opgemerkt, dat ook de Nederlandse bedrijven het tijdperk van de achter zijn bureau blijvende „,boekhouder" reeds lang achter zich hebben. Overigens gaat het hier vooral om de vraag, hoe het te dien aanzien stond in onze literatuur.

Ter beantwoording van deze vraag zal het nodig zijn verschillende Nederlandse schrijvers, die aan het onderwerp aandacht hebben geschonken, te citeren, waarbij zal blijken, dat ook door hen de ,interpretation" en ,,recommandation" reeds zijn gezien als essentiële taken van de administrateur.

De eerste afgeronde gedachte heb ik aangetroffen in een artikel „,Budget-controle" in het nummer van 15 november 1930 van ,De Naamloze Vennootschap" van de hand van Drs. J. G. Stridiron, bevattende een verslag van de in dat jaar in Genève gehouden conferentie van het „International Institute for Scientific Management".

Onder meer treft men in dit verslag de volgende passage aan.

,In de eerste plaats moet een organisatie-schema bestaan met duidelijke omschrijving van ieders taak en verantwoordelijkheid.

m a b blz. 299 
Daarnaast moet er een administratie zijn, die berust op goed doordachte grondslagen, welke systematisch worden doorgevoerd, zodat benodigde en juiste informaties te geven zijn. Hiervoor is het niet al. leen noodzakelijk, dat men instructies geeft, waaruit duidelijk blijkt, hoe elk administratief onderdeel te behandelen is, maar de administratie moet ook voeling houden met de commerciële en technische afdelingen, om de cijferbehoeften van deze afdelingen te leren kennen en ze service te geven.

Het gehele administratieve apparaat dient dus afgesteld te zijn op 2 grondgedachten, logische opbouw en systematische uitwerking benevens service-verlening aan de commerciële en technische afdeling.

Het is nodig een apparaat in het leven te roepen voor de organisatie en administratie van het budget, hoewel natuurlijk de leiding van het concern de beslissende stem heeft over de inhoud van de budgetten. Een centrale afdeling met een verantwoordelijke leider zal geschapen moeten worden, om de afdelingsbudgetten te coördineren. Dit wordt de centrale Budget-afdeling.

In de U.S.A. belast men met de leiding hiervan:

a. De comptroller, dit is iemand, die verantwoordelijk is voor het gehele administratieve apparaat van het concern, d.w.z. accountants-, boekhoud-, kostprijs- en statistiekafdeling.

b. Een aparte man, die alleen verantwoordelijk is aan de Directie (assistent to president).

De laatste manier is de meest juiste gebleken, omdat de directie dan een onafhankelijk en verantwoordelijk man heeft, waarmede $z \mathrm{ij}$ in nauw contact staat en die haar ideeën kan uitvoeren".

Reeds in 1930 werd ons dus hier te lande op het nut van budgettering gewezen, waarbij reeds toen met het Amerikaanse voorbeeld voor ogen de weg werd aangegeven, waarlangs men van de budgettering het grootste nut voor het bedrijf kon bereiken. Aan het slot zal overigens nog aanleiding bestaan op enkele punten uit het artikel van Stridiron terug te komen. Deze punten zijn de verhouding comptroller-intern accountant en de functionele plaats van de comptroller.

Voorts treft men omtrent de betekenis van beide taken een uitvoerige uiteenzetting aan in het nog altijd actuele werk van wijlen J. E. Spinosa Cattela „Budgettering en Budget-contrôle" (1940).

Kortheidshalve moge ik de lezer verwijzen naar het hoofdstuk „De Budgetcontrôle" (blz. 186 e.v.), waarin wordt gewezen op de hoge eisen, die aan de administrateur moeten worden gesteld en op de noodzaak van nauw contact tussen de administrateur en de technische en commerciële organisatie, waarbij eerstgenoemde ,het financiële geweten en de budgetaire vraagbaak moet zijn van de door hen geadministreerde afdelingen." Aldus wordt de administratie datgene, wat $z$ ij in haar beste vorm behoort te zijn nl., ,, a tool of management".

Voorts leest men op blz. 197 e.v., na de opmerking, dat het budget een levend iets moet zijn en elke medewerker moet zijn doordrongen van de overtuiging, dat de budgettering hem kan helpen fouten in het gevoerde beheer, verspillingen en misrekeningen op te sporen:

,Dit moet de grondgedachte zijn van de voortdurend en regelmatig te houden besprekingen omtrent de budget-resultaten tussen 
verantwoordelijke leider en zijn medewerkers. Tot die medewerkers moeten dan ook gerekend worden zij, die met de samenstelling der budget-overzichten belast zijn."

Tenslotte komt Spinosa Cattela in het hoofdstuk ,Het Budget en de boekhouding" tot de aanbeveling van een gedecentraliseerde boekhouding, echter „onder een sterk centraal gezag van de voorschriften, die ten aan zien van de wijze van boeking zullen gelden".

Het wil mij voorkomen, dat de overeenstemming met de recente omschrijvingen van de taken van de ",controller" zeer treffend $z$ ijn.

Eveneens treft men in de inleiding van het werk van J. van Nimwegen "Grondslagen van de administratieve organisatie" (1ste druk 1946) een paar opmerkingen aan, waaruit blijkt, dat de schrijver aan de taak van interpretation en recommandation van de administrateur grote betekenis toekent:

„Ten gevolge van de nieuwere opvattingen omtrent de betekenis der administratieve functie heeft haar taak zich uitgebreid van de eenvoudige registratie van het vermogen tot algehele contröle en analyse van het bedrijfsgebeuren met alle problemen hieraan verbonden".

En verder:

„Dit alles betekent geenszins, dat de administratie gedoemd is tot een passieve houding ten opzichte van de bedrijfsorganisatie; integendeel, van de administratie zullen menigmaal de impulsen en soms zelfs de adviezen moeten uitgaan om te komen tot een doeltreffende bedrijfsorganisatie in de onderneming, wier geschiedsschrijfster en voorlichtster zij is".

Dat deze gedachte door Van Nimwegen in dit werk niet verder is uitgewerkt, vindt zijn logische verklaring in de omstandigheid, dat hij met het boek vooral op het oog heeft het aangeven van de administratieve technieken.

Ook in het werk van S. A. de Vries ,De administratie van industriële ondernemingen (1ste druk 1946) is aan de taak van voorlichting door de administrateur en hetgeen daarvoor van hem vereist wordt, veel aandacht geschonken. Volstaan wordt met een enkel citaat uit hoofdstuk VII "De resultatenoverzichten", paragraaf 1 .

„Zal de administrateur deze taak van bedrijfseconomisch adviseur van de bedrijfsleiding naar behoren kunnen vervullen dan moet hij niet alleen beschikken over de nodige theoretische en practische kennis van de moderne bedrijfsadministratie en de daarbij toe te passen methoden, maar hij moet ook een diep inzicht hebben in de loop van het fabricage-proces en in de organisatie van het bedrijf. Zal hij bovendien de bedrijfsleider een goed gefundeerd antwoord kunnen geven op al diens vragen, dan moet hij nauwkeurig op de hoogte zijn van het doel, waarvoor deze cijfers worden gevraagd en van het gebruik dat er van gemaakt zal worden. De moderne bedrijfsadministrateur zal dus veel dichter bij het bedrijf moeten staan dan zulks in het verleden met de meeste boekhouders veelal het geval was. Een voortdurend nauw contact met het bedrijf in al zijn geledingen is daarvoor nodig. Gesprekken met de leiders der verschillende afdelingen, maar ook met hun ondergeschikten, moeten dienen om de admini-

$\mathrm{m} \mathrm{a} \mathrm{b}$ blz. 301 
strateur voortdurend op de hoogte te houden met alle veranderingen, die zich in het bedrijf onophoudelijk voltrekken.

Zullen echter de door de administrateur op te stellen overzichten practisch nut hebben, dan moet niet alleen de administrateur zich op de hoogte stellen van de gang van zaken in het bedrijf, maar omgekeerd moet ook de bedrijfsleider en zijn ondergeschikte afdelingschefs zich enig inzicht verwerven in de structuur van de bedrijfsadministratie en in de principes van kostprijsberekening en budgettering."

Uit deze citaten blijkt m.i. duidelijk, dat althans in de Nederlandse vakliteratuur (waarbij ik t.a.v. de keuze niet gestreefd heb naar volledigheid) reeds geruime tijd is aangedrongen op het activeren van de administrateur en zijn administratie op een even breed vlak als thans ten aanzien van de controller wordt gesteld. Ik moet dan ook constateren, dat in de omschrijving van de taken van de controller, zoals men die bij Van der Schroeff of in de Amerikaanse literatuur aantreft ten opzichte van de taken, zoals die hier te lande ten aanzien van de administrateur reeds waren onderkend, geen nieuwe gezichtspunten zijn te ontdekken. Het is natuurlijk niet uitgesloten, dat men bij een voldoende waarneming van de organisatie van de Nederlandse en van de Amerikaanse bedrijven tot de conclusie moet komen, dat in de V.S. van de administratie en van zijn topfunctionaris een meer omvattend en efficiënter gebruik wordt gemaakt dan bij ons, ook indien men deze waarneming zou verrichten bij vergelijkbare ondernemingen; zo dit het geval is, dient gezegd te worden, dat de vakliteratuur in ons land in ieder geval de weg reeds heeft gewezen, waarlangs de administratie niet alleen een "tool of management" kan worden, doch ook op welke wijze dan dit gereedschap doelmatig kan worden gebruikt. Dat bij ons de leider van deze werkzaamheden nog steeds ,chef van de administratie" werd genoemd en geen "controller", is eigenlijk weinig interessant.

Ik hoop, dat reeds uit het voorgaande is gebleken, dat het geenszins mijn bedoeling is geweest afbreuk te doen an de betekenis van de vooral door Van der Schroeff hier te lande gehouden pleidooien tot activering van de administratie. Ik meen integendeel, dat door het zoeken van de aansluiting met de stand van het vraagstuk in ons land wellicht bijgedragen kan wordan tot die activering, in zoverre men misschien tot de ontdekking komt, dat men reeds veel in de goede richting heeft gedaan en het bereiken van het door Van der Schroeff gepropageerde doel nog slechts „, een stap" is. Dat hem dit niet zit in de naam ,"controller", doch dat het daarbij gaat om een efficiënte administratie met budgettering en het confronteren tot op grote diepte van budget en werkelijkheid, behoeft geen nader betoog.

Naast de analyse van de taken, welke door de voldoende voor zijn veel omvattende werkzaamheden berekende topman van de aldus ,geactiveerde" administratie en het onder hem ressorterende apparaat moeten worden vervuld, is het nog een vraag van betekenis, welke plaats deze topman in de hiërarchie van de onderneming dient in te nemen. Met name gaat het daarbij over de vraag, of hij deel zal moeten uitmaken van de hoogste leiding in de onderneming, dar wel zijn plaats krijgt toegewezen in de rechtstreeks daaronder ressorterende subalterne leiding.

Benadert men deze vraag vanuit de functie en de taak van de ,.control- 
ler" zoals deze hierboven zijn gereleveerd, dan luidt m.i. het antwoord, dat de controller geen deel moet uitmaken van de hoogste leiding. Immers, ook volgens Van der Schroeff is de functie een staffunctie, welke zijn uitdrukking vindt in de ,,interpretation", ,recommandation" en ,presentation" ten behoeve van alle geledingen in het bedrijf. Naar mijn mening zou het gezag in de zin van bevelvoerende macht, dat de controller zou verkrijgen door zijn opneming in de hoogste leiding eerder storend zijn dan nuttig. In deze functie gaat het niet om het opleggen van conclusies, doch om het geven van adviezen en het aandragen van zodanig toegelicht cijfermateriaal en met redenen omklede overwegingen, dat degenen, voor wie dit alles bestemd is, zelf tot een gefundeerde beslissing kunnen komen. Nogmaals, het wil mij voorkomen, dat deze ,,adviezen en raadgevingen", vooral t.o.v. niet tot de hoogste leiding behorende functionarissen, het karakter zouden gaan krijgen van bevelen, omdat zij dan in de controller de hoogste leiding zelve vertegenwoordigd zullen zien. Het gevaar van "controller-ridden" te zijn, is dan m.i. zeker niet denkbeeldig. En in ieder geval is dan het risico zeer reëel, dat de verantwoordelijkheden worden scheef getrokken. Trouwens, vloeit deze constatering niet reeds rechtstreeks voort uit de staffunctie van de controller? In dit verband merk ik nog op, dat ik een toevoeging nodig acht aan de bekende uitspraak ,the controller is not suffered, he is enjoyed, $\mathrm{nl}$......... mits de hem gegeven macht de pret niet bederft.

Dat men in de Amerikaanse literatuur en de daarin voorkomende organisatie-schema's de controller veelal aantreft onder de "vice-presidents" is met het bovenstaande geenszins in strijd. De hoogste leiding berust daar nl. bij de ,board of directors" en de "president" en de bevoegdheden van de vice-presidents worden door hem bij wijze van delegatie aan de vicepresidents gegeven. Hoewel vergelijkingen altijd moeilijk zijn, meen ik, dat de verhouding tussen de president en de vice-presidents in Amerika ongeveer gelijk te stellen is aan bij ons de verhouding tussen de als zodanig in de statuten der N.V. genoemde directie (de hoogste leiding) en de onderdirecteuren.

Ook bij aanvaarding van de conclusie, dat de controller als zodanig geen deel moet uitmaken van de hoogste leiding spreekt het vanzelf, dat bij die hoogste leiding in de onderneming in voldoende mate de kennis van de financiële en de algemeen- en bedrijfseconomische problemen aanwezig moet zijn. Gegeven de gecompliceerdheid van het huidige economische leven in het algemeen en van de meeste bedrijven, zal men ook bij ondernemingen van niet al te grote omvang reeds tot de conclusie komen, dat een financieel en economisch deskundige in de hoogste leiding aanwezig dient te zijn om mede de verantwoordelijkheid voor de bestuursbesluiten, welke voor een niet gering deel op zijn oordeel gebaseerd zullen zijn, te dragen. Tot deze conclusie zal men komen, ook met erkenning van de juistheid van de opvatting, dat de leiding niet op elk onderdeel van haar besluitvorming ., deskundig" behoeft te zijn.

Ter verduidelijking zij hier opgemerkt, dat ik in het kader van het bovenstaande het oog heb op een meerhoofdige leiding in de onderneming. Naar mijn mening dient daarvan ook gesproken te worden, indien één van de leden van het collegiale bestuur als voorzitter vooral een coördinerende taak heeft, resp. zo nodig bij verschillen van inzicht een beslissende stem heeft.

Overigens ligt de constatering van het nut van het aanwezig zijn van een financieel en bedrijfs-economisch deskundige in de hoogste leiding 
van vele ondernemingen eigenlijk voor de hand. Deze conclusie is eerst in de laatse decennia actueel geworden door het gecompliceerder worden van de financiële en economische problemen en doordat daarmede de betekenis van de deskundigheid op die gebieden voor de beslissingen toenam. Te verwonderen is het wel, dat tegenover de vanzelfsprekendheid, waarmede de technische en commerciële deskundigheid als noodzakelijke elementen in de hoogste leiding zijn aanvaard, dit met de financiële en economische deskundigheid dikwijls slechts schoorvoetend en zeker niet algemeen het geval was (en wellicht nog niet is). Misschien vindt dit verschijnsel zijn oorzaak in de omstandigheid, dat met ",common-sense" en goede technische en commerciële kwaliteiten in de bedrijven reeds veel was bereikt en de financieel en economisch geschoolde op dit punt zijn reputatie nog moest verkrijgen. Vermoedelijk is daarbij ook nog van betekenis, dat een gebrek aan deskundigheid in de leiding op deze punten niet zo gauw ,zichtbaar" is als ten aanzien van de technische en commerciële kwaliteiten.

Tenslotte acht ik het nog nuttig aandacht te schenken aan de verhouding tussen de ,controller" en de interne accountant. De functie van deze laatste is te omschrijven als ,"controleren en adviseren ten behoeve van de leiding". Reeds hiervoor heb ik als mijn mening weergegeven, dat de controller als topman van de administratie in de ,geactiveerde" en ruime zin, van nature een staffunctionaris is; dit is ook het geval met de interne accountant. De functie en laak van deze laatste, eveneens ressorterende rechtstreeks onder de hoogste leiding brengt mede, dat men hem niet aan de controller ondergeschikt kan maken. Ook diens arbeid zal de interne accountant in zijn controle ten behoeve van de hoogste leiding dienen te betrekken en zo gezien zou het onjuist zijn en in strijd met de functie, indien de verklaringen van de interne accountant hun ,eindpunt" zouden moeten vinden bij de controller.

Tegenover dit bezwaar wordt dikwijls aangevoerd, dat het geenszins in strijd is met de beginselen van een doeltreffende organisatie, dat een hogere functionaris door een lagere wordt gecontroleerd en voorts, dat de interne accountant ook de werkzaamheden van de directie in zijn controle moet betrekken en tegen het plaatsen rechtstreeks onder de directie resp. de president-directeur dus hetzelfde bezwaar zou gelden (zie o.m. „De administratie als hulpmiddel bij het bedrijfsbeheer" (4e druk, blz. 30) door drs. M. J. van der Ploeg).

Om met dit laatste punt te beginnen: erkend moet inderdaad worden, dat door de ondergeschiktheid aan de directie een natuurlijk functioneel "gebrek" bestaat t.o.v. de arbeid van de interne accountant en diens verklaring. Niet alleen speelt dit functioneel niet onafhankelijk-zijn een rol bij de bepaling van het controle-programma van de openbare accountant, die van de verklaring van zijn interne collega gebruik maakt, ook in de vervulling van de controle-taak ten behoeve van de hoogste leiding laat dit punt een onvolkomenheid. Het zou buiten het bestek van dit opstel vallen hier thans verder op in te gaan. Intussen moet worden opgemerkt, dat het geconstateerde gebrek nu eenmaal niet te vermijden is; daarmede is echter nog niet aangetoond, dat de te vermijden ondergeschiktheid aan de controller organisatorisch juist is. Integendeel:

a. Het tussen directie en interne accountant schuiven van de controller betekent in feite, dat de behoefte van de leiding aan interne accoun- 
tantscontrole niet wordt gedekt; de controller zal zijn gezag laten gelden, zodat slechts doorgegeven wordt, waarmede hij het eens is.

b. De arbeid van de interne accountant is van andere aard en vereist een andere deskundigheid dan die van de controller; vooral indien de interne accountant zijn functie ,volledig" vervult en het doel van zijn arbeid dus is, dat hij tegenover de leiding kan verklaren, dat hij administratie en jaarrekening heeft gecontroleerd en akkoord bevonden, is siechts hij als deskundige in staat en is ook slechts hij in verband met zijn verantwoordelijkheid verplicht, aard en omvang van zijn arbeid vast te stellen. Ondergeschiktheid aan de controller zou daarom onjuist en ondoelmatig zijn.

Van der Ploeg noemt in zijn eerder genoemde werk nog het argument, dat verreweg de meeste opmerkingen van de interne accountant ter afdoening zullen worden verwezen naar de administrateur. Ik wil hier zelfs aan toevoegen, dat de interne accountant in vele gevallen zelf vele opmerkingen zal afdoen niet alleen met de administrateur, doch met vele andere functionarissen. Daarin ligt echter niet de essentie: het gaat om het noodzakelijke beslissingsrecht voor de interne accountant zelf t.a.v. de vraag wat van zijn opmerkingen de directie dient te bereiken en wat daarvoor niet in aanmerking komt. Nogmaals de behoefte van de hoogste leiding aan interne controle wordt niet gedekt en de functie van de interne accountant wordt wezenlijk aangetast, indien deze beslissing door een andere, onder de directie staande functionaris, moet worden genomen.

Volledigheidshalve moet worden opgemerkt, dat in een goede organisatie volgens Van der Ploeg de administrateur lid dient te zijn van de directie, zo de onderneming daarvoor van voldoende omvang is. Afgezien van de vraag, of deze eis rationeel is (zie hiervoor), is het naar mijn mening ook bij een zodanige organisatie onjuist de interne accountant ondergeschikt te maken aan de administrateur; ook dan zal een rationele vervulling van de functie van de interne accountant het noodzakelijk maken, dat hij het recht en de plicht heeft zich tot de collectieve directie resp. tot de president te wenden, wanneer hij dat noodzakelijk acht. Dat bij een dergelijke organisatie het contact met de administrateur intensiever zal zijn dan dat met de president of met de collectieve directie, doet aan het beginsel niets af. 